\title{
USING THE SIX SIGMA METHODOLOGY IN COMBINATION WITH OTHER TOOLS AND METHODS USED IN INDUSTRIAL PRACTISE
}

\begin{abstract}
The aim of the article is application of Six Sigma method in glue applying process during assembling of IGBT modules of products family SEMiX3 performed in manufacture of SEMIKRON company. There are also used other tools and methods as Pareto diagram, Ishikawa diagram, hypothesis testing, Voice of the customer, involved in DMAIC cycle. There was found, that the most important impact of the glue applying process is the amount of glue. This is related to time savings and also Money savings as well as reduce the number of repairs.
\end{abstract}

Keywords: Six Sigma methodology, glue applying process, methods and tools, DMAIC cycle, industrial practise

\section{Introduction}

The manufacturing organization is situated in Western Slovakia and deals with the manufacturing of diodes, modules, silicon plates and chips used for automotive, energetics, handling and transport equipment, for telecommunications, white goods, audio technique, wind power plants etc. It was discovered in last three months by observations that qualitative errors arise in the glue applying process. After the case is installed, pieces are to be repaired by cleaning of the glue. The most repairs must be performed on modules named SEMiX3 (Table 1).

Table 1. Number of repairs on modules SEMiX in last three months (august - septemberoctober)

\begin{tabular}{|l|l|l|l|l|}
\hline Modul SX & $\begin{array}{l}\text { No of produced } \\
\text { pieces / 3 } \\
\text { months }\end{array}$ & $\begin{array}{l}\text { No of repairs / 3 } \\
\text { months } \\
\text { assembling }\end{array}$ & $\begin{array}{l}\text { No of repairs / 3 } \\
\text { months glue } \\
\text { applying }\end{array}$ & $\begin{array}{l}\text { No of repairs / 3 } \\
\text { months } \\
\text { measuring }\end{array}$ \\
\hline SEMiX 1S & 6000 & 138 & 750 & 30 \\
\hline SEMiX 1R & 3000 & 126 & 309 & 21 \\
\hline SEMiX 2S & 9000 & 135 & 174 & 42 \\
\hline SEMiX 2R & 6000 & 129 & 78 & 27 \\
\hline
\end{tabular}

\footnotetext{
${ }^{1}$ Ing. Katarína Lestyánszka Škurková, PhD., Institute of Industrial Engineering and Management, Faculty of Materials Science and Technology in Trnava, Slovak University of Technology in Bratislava, J. Bottu 25, 91727 Trnava, e-mail: katarina.skurkova@ stuba.sk
} 


\begin{tabular}{|l|l|l|l|l|}
\hline SEMiX 3 & 47000 & 144 & 39527 & 126 \\
\hline SEMiX 33C & 9000 & 105 & 4956 & 12 \\
\hline SEMiX 13 & 6000 & 102 & 36 & 18 \\
\hline SEMiX 13R & 12000 & 108 & 57 & 27 \\
\hline SEMiX 4S & 45000 & 132 & 2169 & 72 \\
\hline Total & 143000 & 1119 & 48056 & 375 \\
\hline
\end{tabular}

Source: SÝKOROVÁ J. 2016

Therefore, it was necessary to implement the statistical control into the glue appying process within Six Sigma methodology and other chosen methods and tools used in industrial practise, and the chosen product was the SEMiX 3 module.

The moduls SEMiX can be seen in Figure 1.

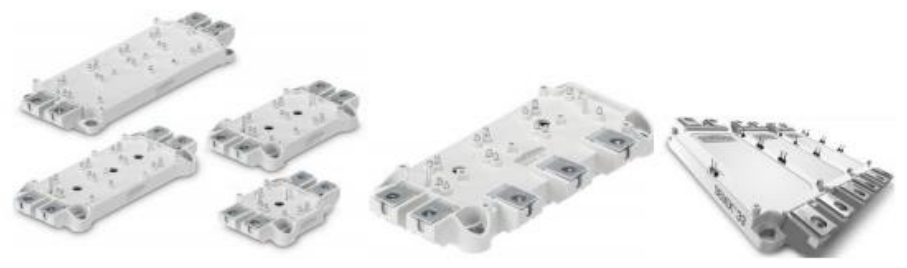

Source: SÝKOROVÁ J. 2016

Fig. 1. Power modules.

Based on the results of final inspection it was discovered that the most errors are caused in the glue applying process. Therefore it was built the Pareto chart (Figure 2).

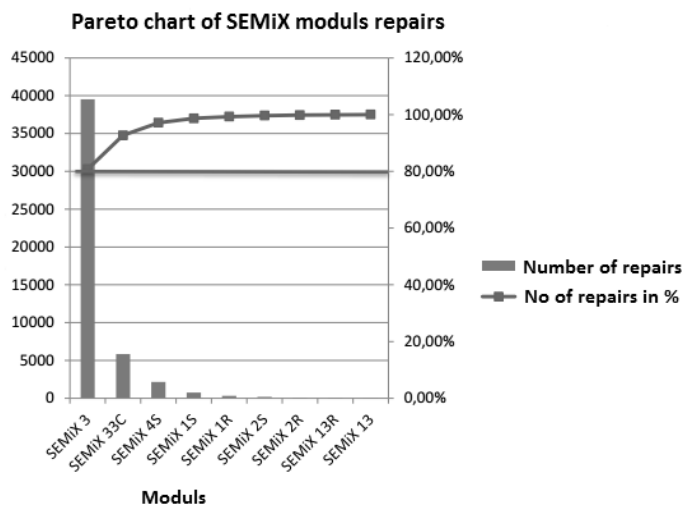

Fig. 2. Pareto chart.

Source: SÝKOROVÁ J. 2016 
Cleaning the modules from the glue means for the company time loss and the loss of income and quality as well. Therefore, the need for improvement of the glue applying process has come from the company's side, IGBT modules family SEMiS 3 by Six Sigma methodology. The target of the Six Sigma project is to reduce the number of these repairs to a minimum, but preferably their full removal.

The monitoring and evaluation of manufacturing process capability presents one of the methods for ensuring and improving processes in the manufacturing organization. It includes the monitoring of stability and normality based on values obtained from the manufacturing process and the calculation of manufacturing process capability indices $\mathrm{C}_{\mathrm{p}}$ and $\mathrm{C}_{\mathrm{pk}}$ (ANDRÁSSYOVÁ Z. et al., 2011).

By determining the process capability, we can isolate the estimated process capability (before starting the production) and permanent process capability. The $\mathrm{C}_{\mathrm{p}}$ index shows the process variability, and the $\mathrm{C}_{\mathrm{pk}}$ index shows the position of the process in a tolerance zone (FERANCOVÁ M. 2013).

In mass production the early detection of defects and taking an appropriate corrective action is nessesary. Before taking any corrective action, the defects need to be diagnosed correctly. The proper classification and identification of a particular defect is fundamental for determination of the cause and appropriate corrective action in order to prevent defect recurrence (SÜTŐOVÁ A. 2013).

\section{Methodology}

The production of SEMiX modules has recently seen an increase in family repairs of the SEMiX 3 modules in the glue application step, where after insertion of the case were occured pieces which must be repaired, cleaned from the glue. The number of repairs was around $84 \%$, and such \% of corrections was unacceptable for the company. At the beginning of November 2015, according to a company's need to be drawn up by the project team to reduce and clarify the problem by glue applying process to the family of SEMiX3 modules. According to the DMAIC cycle it was assembled the structure of the project. At the end of the project there will be calculated saving connected with amount of glue costs, time savings for one worker and also the costs reducing in the glue applying process.

\section{Data collecting}

\section{Pareto chart}

The Pareto principle posits that only a few causes (the vital 20\%) are responsible for the majority (80\%) of problems (HRUBEC J. et al. 2009). Improvement benefits can be leveraged by focusing attention on the key issues (that is, the 20) and while looking 
at critical factors i tis not uncommon to discover and resolve many of the other lesser important problems by default. When check sheet data are plotted on a Pareto chart, the most important problems are revealed. It is customary to plot a pair of graphs a bar graph that displays item percentages sorted in descending order, and a line praph that plots the cumulative percentage of items on the sorted list. These two graphs are then plotted on the same chart. The significant (vital) problems can be separated from the trivial ones by extending a horizontal line from the $80 \%$ point on the y-axix over to the line graph, and then dropping a vertical line perpendicular to the $\mathrm{x}$-axis. In this case $i$ tis clear that improvement efforts should target problems.

All types of problems do not necessarily have an equal impact on quality (AIKENS C.H. 2011).

\section{Cause - and - Effect Diagram}

The cause - and - effect (CE) diagram is also called a fishbone diagram (due to its similarity to the skeletal structure of a fish), and an Ishikawa diagram (in honor of its founder). (ISHIKAWA K. 1982). Once a team decides which problem it wants to solve, possibly from a Pareto analysis, the CE diagram can help it identify candidate causes.

The CE structure is illustrated in Figure 3.

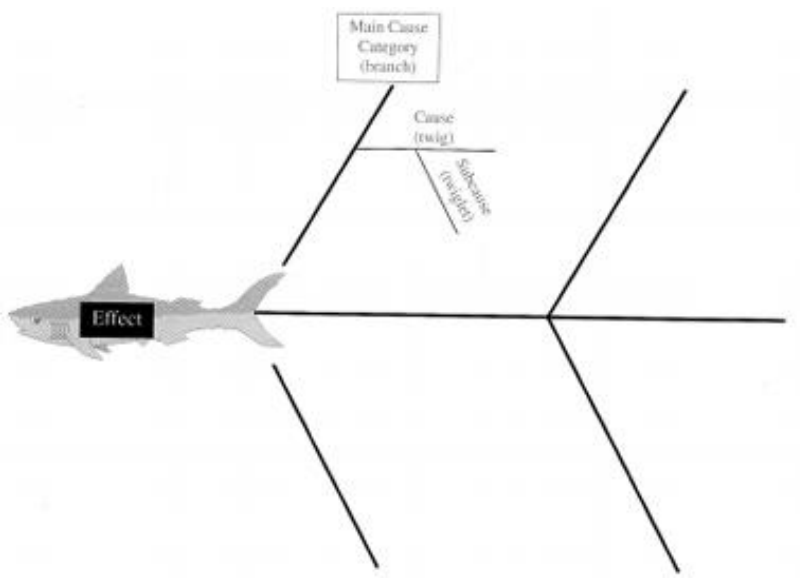

Source: AIKENS C. H. 2011

Fig. 8.3. Ishikawa diagram.

To construct a CE diagram, the problem, or effect, is placed in a box (analogous to the head of the fish). A horizontal line (the backbone) is drawn from the box, and from the backbone angled fishbones are inserted corresponding to each main problem category. This forms the skeleton of the fishbone diagram (KoTUS M., JANKAJOVÁ E., PETRÍK M. 2015). 
Main categories can be anathing relevant to the problem, but the typical ones include materials, methods, personnel, and machines. From each main stem smaller bones (or twigs) are constructed for each candidate cause, and from these, smaller bones (or twiglets) representing subcauses are drawn. The diagram can include as many sublevels as required to get to the root causes.

The CE diagram adds structure to brainstormed ideas. It is important that the team understands that all „causes“ shown on the diagram are merely candidates and have not been proven to be true causes of the stated effect. Consequently, $i$ tis essential that all causes suggested by team members should be listed, no mater how bizarre, zany, or unlikely.

When the team is satisfied that most of the likely causes have been captured, the next step is to narrow the list to just a few for detailed study.

Four guidelines can be helpful in achieving this end.

- Guideline 1. Separate the causes into those that the team can potentially control and those beyond its control. A team in one organization stratified its causes into two fishbones that resembled a pair of kissing fish.

- Guideline 2. Have each team member identify the top three causes - that is, the ones that each individual believes are likely to be major drivers. This can be done most effectively outside a formal meeting. Next, have the team meet, combine everyone's selections, and try to reach consensus (possibly using the nominal group technique) on a short list of three to five causes to investigate further (PETRÍK, 2009).

- Guideline 3. Determine relationships. Focusing on the short list of selected causes, have the team try to understand if an association exists between the effect and each of the suspected causes, and also between each pair of causes. If data are available, scatter plots and statistical correlation analysis can be used to make these determinations.

- Guideline 4. Combine systems thinking with the cause - and - effect relationships. The team should question what feedback mechanisms operate between the effect and the candidate cause - that is, is the feedback loop negative (balancing) or positive (reinforcing)? A negative feedback loop has a self - regulating trigger that causes a modification in behavior. When activated, the cause will induce some desired behavior or result, with respect to the effect. It will in turn have a negative influence on the cause and in essence the roles will reverse. In a balancing cycle, the effect will become a cause - just the opposite of how the relationship was originally perceived. In the case of a positive or reinforcing feedback loop, the effect simly signals the cause to keep doing what it is doing. Whether positive or 
negative, there is usually a time lapse between when the feedback is received and when the system responds (AIKENS C.H. 2011).

To determine the type of feedback loops, the following question is directed at each causation branch: How is the behavior in the causation branch altered as a result of variability (i.e., increases and decreases) in the measured effect?

In the example, whenever the defect rate increases, the frequency of ad recycles diminishes the overall productivity of the ad preparation process. When this happens, deadlines, so vital in the newspaper industry, are jeopardized and pressure reverberates back up the value stream. Then, through the trigger mechanisms, the roles reverse. The effect now becomes the driver, activating improvement efforts in training and editing.

Triggers occur whenever there is a positive trend (or unacceptable level) of ad recycles, or experienced personnel leave and have to be replaced by inexperienced ones. As improvement efforts in training and editing begin to work, the roles reverse again and the trend in ad recycles changes sign and becomes a negative trend. When it reaches an acceptable level the triggers cause a slackening of the improvement efforts, representing yet another reversal of roles.

Machine crashes and lack of standard methods are examples of positive feedback loops. As the number of recycles increases, rework is comingled with new work, and the total workload grows. With increased work and tightening deadlines, workers must increase their pace just to keep up. With mounting pressures, panic sets in and workers are more likely to cut corners (looking for shortcuts) and make mistakes. Inconsistent methods across the work group become even more nonstandard and machine crashes become more prevalent, driving the defect rate even higher (JANKAJOVÁ E., KOTUS M. 2015).

\section{SIPOC diagram}

Many recent inquiries and discussions have focused on the SIPOC diagram - a tool used in the Six Sigma methodology. Because of the interest level, a further explanation is presented here along with a sample and template for your use.

A SIPOC diagram is a tool used by a team to identify all relevant elements of a process improvement project before work begins. It helps define a complex project that may not be well scoped, and is typically employed at the Measure phase of the Six Sigma DMAIC (Define, Measure, Analyze, Improve, Control) methodology. It is similar and related to process mapping and 'in/out of scope' tools, but provides additional detail.

The tool name prompts the team to consider the suppliers (the 's' in SIPOC) of your process, the inputs (the 'i') to the process, the process (the ' $p$ ') your team is improving, the outputs (the ' $\mathrm{o}$ ') of the process, and the customers (the ' $\mathrm{c}$ ') that receive 
the process outputs. In some cases, requirements of the customers can be appended to the end of the SIPOC for further detail (KORENKO M. 2015).

The SIPOC tool is particularly useful when it is not clear:

- Who supplies inputs to the process?

- What specifications are placed on the inputs?

- Who are the true customers of the process?

- What are the requirements of the customers? (www.isixsigma.com)

\section{Steps to Complete the SIPOC Diagram}

SIPOC diagrams are very easy to complete. Here are the steps you should follow:

1. Create an area that will allow the team to post additions to the SIPOC diagram. This could be a transparancy (to be projected by an overhead) made of the provided template, flip charts with headings (S-I-P-O-C) written on each, or headings written on post-it notes posted to a wall.

2. Begin with the process. Map it in four to five high level steps.

3. Identify the outputs of this process.

4. Identify the customers that will receive the outputs of this process.

5. Identify the inputs required for the process to function properly.

6. Identify the suppliers of the inputs that are required by the process.

7. Optional: Identify the preliminary requirements of the customers. This will be verified during a later step of the Six Sigma measurement phase.

8. Discuss with project sponsor, Champion and other involved stakeholders for verification. (www.isixsigma.com).

\section{The PDCA Cycle}

The Plan - Do - Check - Act (PDCA) cycle has been widely accepted as the basic model for the process of continuous improvement, and has its roots in the work of Walter Shewhart.

In 1950 Deming instructed the Japanese on how to apply the Shewhart product development cycle which involves five steps: design the product, build the product, put the product on the market, use market research to test the product in service, and use customer feedback to redesign the product, and continue the cycle (KOLSAR, 1994). The Shewhart cycle inspired the Japanese to develop a general problem solving process called the PDCA cycle that became popular due to its simplicity and logic (MizunO, 1984). The process consists of four steps: Plan, Do, Check, and Act (Figure 4). 


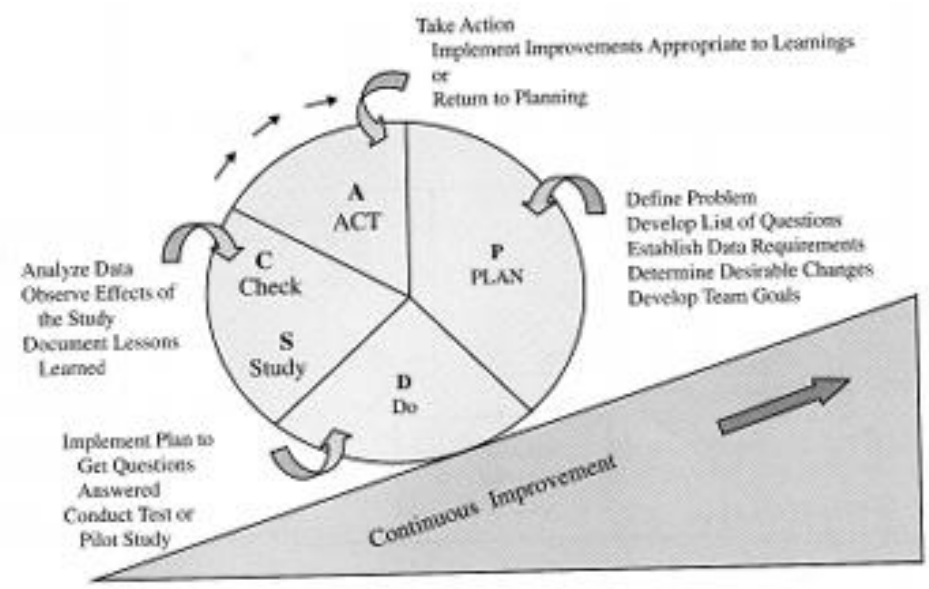

Source: AIKENS C. H. 2011

Fig. 4. PDCA Cycle.

In the Plan step, the problem solvers grapple with issues sucha s why the particular issue iw worthy of consideration, what is known about the problem, how the problem should be defined, what questions need to be answered, the best way to obtain answers to those questions, who will do what tasks, and how will each task be best accomplished.

During the Do step problem solvers implement their plan attempting to collect the data that will answer their questions and aid in the resolution of the problem at hand. This step can entail a broad spectrum of activities ranging from collecting performance data to conducting a designed statistical experiment.

The Check step is where the data (or experimental outcomes) are analyzed and transformed into new knowledge aimed at addressing the issues and answering the questions raised during the Plan step. The new insights and learnings will either provide the basis for action or generate a new set of issues and questions (KORENKO M. 2012).

The final step in the cycle is to Act on what was learned. Actions can include piloting a new method, implementing new controls, solving the stated problem, or simply recognizing that the team was trying to answer the wrong set of questions or the set was incomplete. In the latter case, the process cycles back to the Plan step and the process repeats.

Deming preferred the term PDSA cycle - substituting a Study step for the Check step - a process that he claimed was more in keeping with Shewhart's intent and that is more supportive of team - oriented problem solving (DEMING W.E. 2000). It was 
Deming's contention that in a team setting progress is made when three conditions are met.

1. Every team member has the opportunity to contribute ideas that are considered and ultimately become part of a sensensus position.

2. Team learning takes place.

3. The team makes periodic fresh starts from a higher level of understanding.

\section{Voice of the Customer}

The "voice of the customer" is a process used to capture the requirements/ feedback from the customer (internal or external) to provide the customers with the best in class service/product quality. This process is all about being proactive and constantly innovative to capture the changing requirements of the customers with time.

The "voice of the customer" is the term used to describe the stated and unstated needs or requirements of the customer. The voice of the customer can be captured in a variety of ways: Direct discussion or interviews, surveys, focus groups, customer specifications, observation, warranty data, field reports, complaint logs, etc.

This data is used to identify the quality attributes needed for a supplied component or material to incorporate in the process or product.(www.isixsigma.sk).

\section{Here are 4 key areas to consider when building the VoC program:}

Capture: It's important to identify customer listening posts both internally and externally. Surveys are the easiest and most common way to establish listening posts across all customer touch-points and departments.

Analyze: After capturing key insights, then analyze feedback in real-time. It's important to deliver clear and actionable insight to the right employee stakeholders.

Act: Successful VoC programs put in the best position to act on real-time insight. Knowing where the problem areas are allows the team to take corrective action.

Monitor: Continuous monitoring helps to track the results over time. Having a realtime pulse on the customers helps uncover patterns to see where to make improvements across the enterprise (www.qualtrics.com).

\section{Characteristics of the best VOC programs}

- Connect multiple types of feedback across data channels

- Provide automatic collaboration across functional departments

- Incorporate the voice of the employee

- Leverage dashboards and reports that integrate and display information from multiple customer voices regardless of source, survey or time 
- Deliver clear ROI and business results (www.qualtrics.com).

\section{Hypothesis testing}

A hypothesis test is a statistical test that is used to determine whether there is enough evidence in a sample of data to infer that a certain condition is true for the entire population.

A hypothesis test examines two opposing hypotheses about a population: the null hypothesis and the alternative hypothesis. The null hypothesis is the statement being tested. Usually the null hypothesis is a statement of "no effect" or "no difference". The alternative hypothesis is the statement you want to be able to conclude is true.

Based on the sample data, the test determines whether to reject the null hypothesis. You use a p-value, to make the determination. If the p-value is less than or equal to the level of significance, which is a cut-off point that you define, then you can reject the null hypothesis.

A common misconception is that statistical hypothesis tests are designed to select the more likely of two hypotheses. Instead, a test will remain with the null hypothesis until there is enough evidence (data) to support the alternative hypothesis. (www.minitab.com).

A statistical hypothesis is an assumption about a population parameter. This assumption may or may not be true. Hypothesis testing refers to the formal procedures used by statisticians to accept or reject statistical hypotheses.

\section{Statistical hypotheses}

The best way to determine whether a statistical hypothesis is true would be to examine the entire population. Since that is often impractical, researchers typically examine a random sample from the population. If sample data are not consistent with the statistical hypothesis, the hypothesis is rejected.

There are two types of statistical hypotheses.

- Null hypothesis. The null hypothesis, denoted by $\mathrm{H}_{0}$, is usually the hypothesis that sample observations result purely from chance.

- Alternative hypothesis. The alternative hypothesis, denoted by $\mathrm{H}_{1}$ or $\mathrm{H}_{\mathrm{a}}$, is the hypothesis that sample observations are influenced by some non-random cause.

For example, suppose we wanted to determine whether a coin was fair and balanced. A null hypothesis might be that half the flips would result in Heads and half, in Tails. The alternative hypothesis might be that the number of Heads and Tails would be very different. Symbolically, these hypotheses would be expressed as 
$\mathrm{H}_{0}: \mathrm{P}=0.5$

$\mathrm{H}_{\mathrm{a}}: \mathrm{P} \neq 0.5$

Suppose we flipped the coin 50 times, resulting in 40 Heads and 10 Tails. Given this result, we would be inclined to reject the null hypothesis. We would conclude, based on the evidence, that the coin was probably not fair and balanced. (www.stattrek.com).

Can we accept the null hypothesis?

Some researchers say that a hypothesis test can have one of two outcomes: you accept the null hypothesis or you reject the null hypothesis. Many statisticians, however, take issue with the notion of ,accepting the null hypothesis“. Instead, they say: you reject the null hypothesis or you fail to reject the null hypothesis.

Why the distinction between ,acceptance“ and „failure to reject“? acceptance implies that the null hypothesis is true. Failure to reject implies that the data are not sufficiently persuasive for us to prefer the alternative hypothesis over the null hypothesis. (www.stattrek.com).

\section{Hypothesis tests}

Statisticians follow a formal process to determine whether to reject a null hypothesis, based on samle data. This process, called hypothesis testing, consists of four steps:

1. State the hypothesis. This involves stating the null and alternative hypotheses. The hypotheses are stated in such a way that they are mutually exclusive. That is, if one is true, the other must be false.

2. Formulate an analysis plan. The analysis plan describes how to use sample data to evaluate the null hypothesis. The evaluation often focuses around a single test statistic.

3. Analyze sample data. Find the value of the test statistic (mean score, proportion, $t$ statistic, $\mathrm{z}$ - score, etc.) described in the analysis plan.

4. Interpret results. Apply the decision rule described in the analysis plan. If the value of the test statistic is unlikely, based on the null hypothesis, reject the null hypothesis (www.stattrek.com).

\section{Decision Errors}

Two types of errors can result from a hypothesis test.

- Type I error. A Type I error occurs when the researcher rejects a null hypothesis when it is true. The probability of committing a Type I error is called the significance level. This probability is also called alpha, and is often denoted by $\alpha$. 
- Type II error. A Type II error occurs when the researcher fails to reject a null hypothesis that is false. The probability of committing a Type II error is called Beta, and is often denoted by $\beta$. The probability of not committing a Type II error is called the Power of the test.

\section{Decision Rules}

The analysis plan includes decision rules for rejecting the null hypothesis. In practice, statisticians describe these decision rules in two ways - with reference to a P-value or with reference to a region of acceptance.

- P-value. The strength of evidence in support of a null hypothesis is measured by the $\mathbf{P}$-value. Suppose the test statistic is equal to $S$. The P-value is the probability of observing a test statistic as extreme as $S$, assuming the null hypotheis is true. If the P-value is less than the significance level, we reject the null hypothesis.

- Region of acceptance. The region of acceptance is a range of values. If the test statistic falls within the region of acceptance, the null hypothesis is not rejected. The region of acceptance is defined so that the chance of making a Type I error is equal to the significance level.

The set of values outside the region of acceptance is called the region of rejection. If the test statistic falls within the region of rejection, the null hypothesis is rejected. In such cases, we say that the hypothesis has been rejected at the $\alpha$ level of significance.

These approaches are equivalent. Some statistics texts use the P-value approach; others use the region of acceptance approach. In subsequent lessons, this tutorial will present examples that illustrate each approach. (www.stattrek.com).

\section{One - Tailed and Two - Tailed Tests}

A test of a statistical hypothesis, where the region of rejection is on only one side of the sampling distribution, is called a one-tailed test. For example, suppose the null hypothesis states that the mean is less than or equal to 10 . The alternative hypothesis would be that the mean is greater than 10 . The region of rejection would consist of a range of numbers located on the right side of sampling distribution; that is, a set of numbers greater than 10 .

A test of a statistical hypothesis, where the region of rejection is on both sides of the sampling distribution, is called a two-tailed test. For example, suppose the null hypothesis states that the mean is equal to 10 . The alternative hypothesis would be that the mean is less than 10 or greater than 10 . The region of rejection would consist of a range of numbers located on both sides of sampling distribution; that is, the region of 
rejection would consist partly of numbers that were less than 10 and partly of numbers that were greater than 10. (www.stattrek.com).

\section{The DMAIC Tactics}

The Six Sigma improvement model, called Define - Measure - Analyze - Improve Control (DMAIC) (pronounced Duh - May- Ick), adds an additional step to the PDCA cycle. The PDCA and DMAIC models are grounded in a common philosophy - use data to create knowledge relative to a problem and then act on the knowledge to solve the problem. The tactics of DMAIC are summarized below.

DMAIC is a data-driven quality strategy used to improve processes. It is an integral part of a Six Sigma initiative, but in general can be implemented as a standalone quality improvement procedure or as part of other process improvement initiatives such as lean (PETRÍK J., GENGEL' P. 2014).

DMAIC is an acronym for the five phases that make up the process:

- Define the problem, improvement activity, opportunity for improvement, the project goals, and customer (internal and external) requirements.

- Measure process performance.

- Analyze the process to determine root causes of variation, poor performance (defects).

- Improve process performance by addressing and eliminating the root causes.

- Control the improved process and future process performance.

The DMAIC process easily lends itself to the project approach to quality improvement encouraged and promoted by Juran. (www.asq.org.).

\section{Improvement model relationships}

A feature that distinguishes DMAIC from other improvement models is the provision for "tollgates" between each of the phases. The tollgates represent milestone events when the improvement team meets formally with senior management and other project participants to review progress and ensure that the project stays on target and in alignment with cororate goals. Figure 5 shows how the three improvement models are related. 


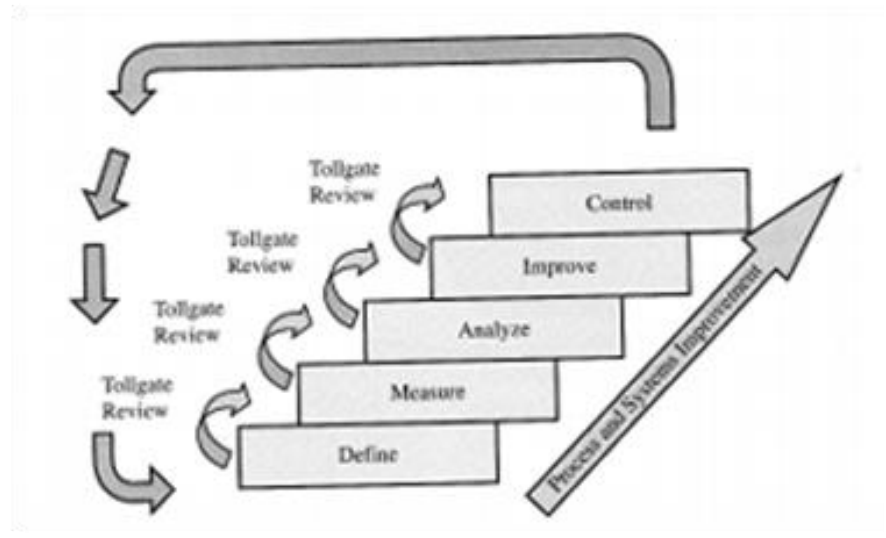

Fig. 5. Six Sigma

Improvement Model.

Source: AIKENS C. H. 2011

\section{Results and discussion}

The beginning of the problem solution was to define the content of the individual steps of DMAIC cycle.

Chosen steps are supplemented with some other tools and methods used in industrial practise and help to achieve the target of each step. The target of the whole Six Sigma project was to reduce the number of repaired pieces from $84 \%$ to $42 \%$.

\subsection{Define}

In the first step of the project solution, it was necessary to define basic project data.

Project name: Reduction of the number of corrections in the glue process IGBT modules family SEMiX3.

Project team: project manager, production technologist SEMiX, modules glueing technologist SEMiX, quality engineer, servise technician, SEMiX production planner, as a konzultant was added the diploma student as well.

Project duration: November, 1th 2015 till February $29^{\text {th }} 2015$

Issue: Increased number of repaired pieces in the IGBT modules family SEMiX glue applying process.

Project target: Reducing the number of repaired pieces in the IGBT module family SEMiX glue applying process from $84 \%$ to $42 \%$.

On the SEMiX 3 family modules, after the case has been inserted, there are discovered pieces needed repair or clean the modules from the glue. This nonconformity causes that the modules cleaning extend the glue applying operation, increase the costs as well as the occurrence of non - conformities in the next production process - by potting, measuring, or by modules packing. But also it can 
cause a customer's complaint in the case when the worker does not notice the leaked glue.

At the beginning, the project team was scheduled to split each phases of the project into the DMAIC model, which can be seen in Table 2 .

The team tried to get the timetable and the whole team tried and did everything to make them timed, but there were also minor delays associated with watting for expressing the parent undertaking in Germany.

Table 2. Timetable of the project

\begin{tabular}{|l|l|l|}
\hline \multicolumn{3}{|c|}{ Timetable of the project } \\
\hline Project phase & Start & End \\
\hline Define & November 1st, 2015 & November 2nd, 2015 \\
\hline Measure & November 3th, 2015 & November 8th, 2015 \\
\hline Analyse & November 9th, 2015 & November 18th, 2015 \\
\hline Improve & November 18th, 2015 & November 31st, 2015 \\
\hline Control & December 1st, 2015 & February 2nd, 2016 \\
\hline
\end{tabular}

Source: SÝKOROVÁ J. 2016

The Define phase consists of the analysis of the data from the previous period and the beginning of the project. We tried to find out all the process data from the available documentation at the company about the glue applying process modules IGBT. We observed the development of number of non - conformities.

It was necessary for the company to know the customer's demands and opinions. In the Table 3 can be seen the customer's requirements.

Table 3. Voice of the customer

\begin{tabular}{|c|c|c|}
\hline Voice of the customer & Significance & CTQ \\
\hline Functional module & Reduced costs of the process & $\begin{array}{c}\text { Reducing the scrap / Reducing the } \\
\text { downtime }\end{array}$ \\
\hline $\begin{array}{c}\text { Module with the right } \\
\text { parameters }\end{array}$ & $\begin{array}{c}\text { Reduced costs of the process } \\
\text { / Reducing the amount of } \\
\text { nonconforming material }\end{array}$ & $\begin{array}{c}\text { Reducing the downtime / Quality } \\
\text { of incoming materials }\end{array}$ \\
\hline $\begin{array}{c}\text { Clean undamaged } \\
\text { module }\end{array}$ & $\begin{array}{c}\text { Reducing the amount of } \\
\text { nonconforming material }\end{array}$ & $\begin{array}{c}\text { Quality of incoming materials / } \\
\text { Human factor }\end{array}$ \\
\hline
\end{tabular}

Source: SÝKOROVÁ J. 2016

In the project, there was defined the SIPOC diagram, which can be seen in Figure 6. It helps us to understand the process, to define the inputs and outputs, who is the 
supplier and who is the customer. It can shows the process to people in the company, but also in the outside.

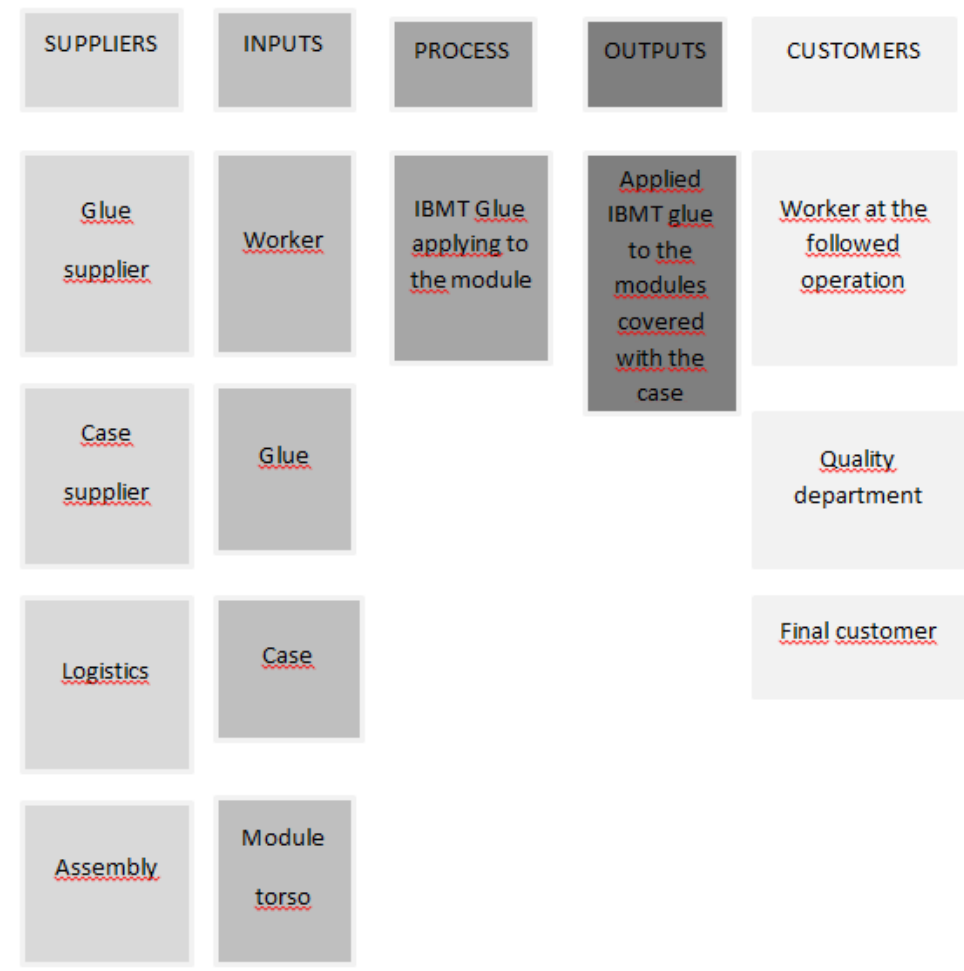

Source: SÝKOROVÁ J. 2016

Fig. 6. SIPOC diagram.

\subsection{Measure}

In the Measure phase we started from the Table 1, which gave to us information that the most repairs occur by modules glueing operation, especially modules family SEMiX3.

After defining the time division of the project phases, we determined the current status in the module glueing process by data from the repository record form. In this form workers recorded bad - cleaned pieces. From this form we compiled Table 4. This Table contains the percentage of cleaned pieces, the sigma level as well as the process target value which we want to achieve. 
Table 4. Statistical data in the glue applying process on IGBT modules family SEMiX3 and

the process target value

\begin{tabular}{|l|c|c|c|c|c|c|}
\hline \multicolumn{1}{|c|}{ Month } & $\begin{array}{c}\text { No of } \\
\text { sticked } \\
\text { pieces }\end{array}$ & $\begin{array}{c}\text { No of } \\
\text { cleansed } \\
\text { pieces }\end{array}$ & $\begin{array}{c}\text { \% of } \\
\text { cleansed } \\
\text { pieces }\end{array}$ & $\begin{array}{c}\text { Sigma level } \\
\text { at the } \\
\text { beginning }\end{array}$ & $\begin{array}{c}\text { Target } \\
\text { value \% } \\
\text { of } \\
\text { cleansed } \\
\text { pieces }\end{array}$ & $\begin{array}{c}\text { Target } \\
\text { sigma } \\
\text { value }\end{array}$ \\
\cline { 1 - 5 } August 2015 & 9500 & 7707 & 81.13 & 1.74 & & \\
\cline { 1 - 5 } $\begin{array}{l}\text { September } \\
\text { 2015 }\end{array}$ & 16500 & 13792 & 83.59 & 1.79 & \multirow{2}{*}{2.90} \\
\cline { 1 - 5 } October 2015 & 21000 & 18028 & 85.85 & 1.68 & & \\
\hline Value & 47000 & 39527 & 84.10 & 1.70 & & \\
\hline
\end{tabular}

Source: SÝKOROVÁ J. 2016

The sigma level was calculated according to the pattern DPMO, where we defined the number of errors types is 2 . The first type of error is leaking glue and the second one may be a lack of glue causing leakage of silgel by potting.

At this phase the team deals with the time loss caused by cleaning the modules family SEMiX3 from the glue. This time loss is necessary in terms of productivity and profitability of the company. In the Table 5 can be seen the worker's fime frame and in the Table 6 can be seen the timeframe of SEMiX3 machine by modules glueing.

Table 5. The workers timetable by module glueing operation

\begin{tabular}{|c|c|c|c|c|}
\hline \multicolumn{5}{|c|}{ Glueing by worker } \\
\hline No. & $\begin{array}{l}\text { Part of the proces and the } \\
\text { measurement point }\end{array}$ & $\begin{array}{l}\text { Reference } \\
\text { quantity }\end{array}$ & $\begin{array}{l}\text { Average time } \\
\text { (s)/metal } \\
\text { sheet }\end{array}$ & $\begin{array}{l}\text { Average time } \\
\text { (s) / } 1 \text { pcs }\end{array}$ \\
\hline \multirow[t]{2}{*}{1} & Fit the case & \multirow{2}{*}{9} & \multirow{2}{*}{51.5} & \multirow{2}{*}{5.7} \\
\hline & Fit the last pcs & & & \\
\hline \multirow[t]{2}{*}{2} & $\begin{array}{l}\text { Insert the module into the } \\
\text { bender }+ \text { put on a metal sheet }\end{array}$ & \multirow[t]{2}{*}{1} & \multirow[t]{2}{*}{11.2} & \multirow[t]{2}{*}{11.2} \\
\hline & Insert next module & & & \\
\hline \multirow[t]{2}{*}{3} & $\begin{array}{l}\text { Cleaning the corners of the } \\
\text { modules from the adhesive }\end{array}$ & \multirow{2}{*}{10} & \multirow{2}{*}{121.8} & \multirow{2}{*}{12.2} \\
\hline & $\begin{array}{l}\text { Put the metal sheet to the } \\
\text { trolley }\end{array}$ & & & \\
\hline 4 & $\begin{array}{l}\text { Operating of the ionization } \\
\text { chamber }\end{array}$ & 9 & 57.0 & 6.3 \\
\hline \multirow[t]{2}{*}{5} & Operating of the glue device & 9 & 22.0 & 2.4 \\
\hline & \multicolumn{3}{|l|}{ Basic time for one $\mathrm{pc}$} & 37.9 \\
\hline
\end{tabular}




\begin{tabular}{|l|c|}
\hline $15 \%$ surcharge to the basic time & 5.7 \\
\hline Total time with 15\% surcharge & 43.6 \\
\hline The workers capacity & $82.6 \mathrm{pcs} / \mathrm{hour}$ \\
\hline
\end{tabular}

Source: SÝKOROVÁ J. 2016

Table 6. The machine timetable by module gluening operation

\begin{tabular}{|c|c|c|c|c|}
\hline \multicolumn{5}{|c|}{ Gluening machine } \\
\hline No. & $\begin{array}{l}\text { Part of the proces and the } \\
\text { measurement point }\end{array}$ & $\begin{array}{l}\text { Reference } \\
\text { quantity }\end{array}$ & $\begin{array}{l}\text { Average time } \\
\text { (s)/metal } \\
\text { sheet }\end{array}$ & $\begin{array}{l}\text { Average } \\
\text { time (s) / } 1 \\
\text { pcs }\end{array}$ \\
\hline \multirow[t]{2}{*}{1} & $\begin{array}{l}\text { Place the torso carrier in an glue } \\
\text { device }+ \text { feeder control }\end{array}$ & \multirow[t]{2}{*}{9} & \multirow[t]{2}{*}{9.4} & \multirow[t]{2}{*}{1.0} \\
\hline & The terminals checking & & & \\
\hline \multirow[t]{2}{*}{2} & Push the button Start + Gluening & \multirow[t]{2}{*}{9} & \multirow[t]{2}{*}{195.6} & \multirow[t]{2}{*}{21.7} \\
\hline & $\begin{array}{l}\text { Transfer the nedele to the } \\
\text { outgoing position }\end{array}$ & & & \\
\hline \multirow[t]{2}{*}{3} & $\begin{array}{l}\text { Remove the torso carrier from } \\
\text { the glue device }\end{array}$ & \multirow[t]{2}{*}{9} & \multirow[t]{2}{*}{6.5} & \multirow[t]{2}{*}{0.7} \\
\hline & $\begin{array}{l}\text { Put the carrier to the working } \\
\text { table }\end{array}$ & & & \\
\hline \multicolumn{4}{|c|}{ Basic time for one $\mathrm{pc}$} & 23.5 \\
\hline \multicolumn{4}{|c|}{$15 \%$ surcharge to the basic time } & 3.5 \\
\hline \multicolumn{4}{|c|}{ Total time with $15 \%$ surcharge } & 27.0 \\
\hline \multicolumn{4}{|c|}{ Gluening capacity } & $\begin{array}{l}133.2 \\
\text { pcs/hour }\end{array}$ \\
\hline
\end{tabular}

Source: SÝKOROVÁ J. 2016

\subsection{Analyse}

By teamwork we have built an Ishikawa diagram that we have effectively helped to arrange and create an overview of the possible causes of the problem.

The members of the project team have attached seriousness to individual causes from 1 till 5, where the number 5 is the highest seriousness. According this sums we have determined four main causes led to the formation of repairs: glue quantity in the container, component pressure, glue travel, amount of glue used by application to module. The next step was to undertake the main causes for a detailed analysis. The experiments results were analyzed using hypothesis tests about the statistical 
significance of the differences, that arrose in the occurrence of repairs by module glueing between the two tested batches.

- If P - value $>0.05$ the hypothesis H0 is accepted, there is no significant difference between tests,

- If $\mathrm{P}$ - value $<0.05$, the hypothesis $\mathrm{H} 1$ is accepted, there is significant difference between tests.

\section{Testing the amount of glue in the container}

There were made two test with 300 pieces. The first test was made with the half of tested pieces. The glue was applied and the container was full of glue. The second test was made with the half of tested pieces and the glue in the container was only in the minimum quantity.

First test result: 125 cleaned pieces $(83.3 \%)$

Second test result: 130 cleaned pieces $(86.6 \%)$

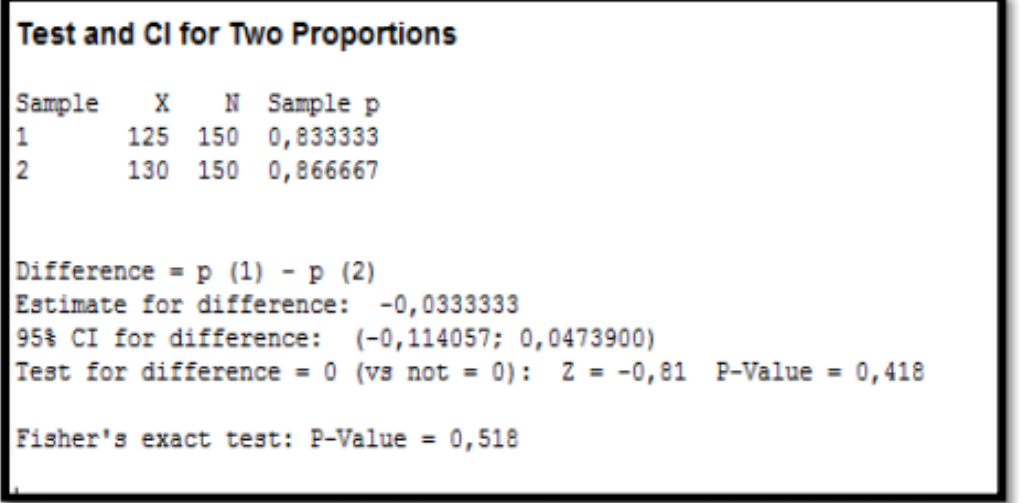

Source: SÝKOROVÁ J. 2016

Fig. 7. Testing the amount of glue in the container

$\mathrm{P}$ - value $=0,418>0,05 \mathrm{H} 0$ is accepted. It means that there is not significant difference and the amount of glue in the container has no influence on occurrence of nonconformities.

\section{Testing the pressure of glue components}

There were made two test with 300 pieces. In the first test we used the standard pressure $12 \pm 4$ bar and in the second test the pressure was $6 \pm 2$ bar.

Results:

First test: Number of cleaned pieces is $125(83.3 \%)$.

Second test: Number of cleaned pieces is $120(80 \%)$. 


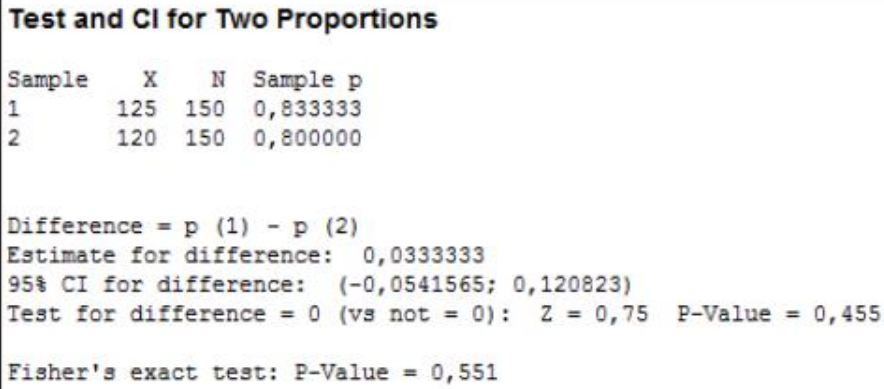

Fig. 8. Testing the pressure of glue components.

Source: SÝKOROVÁ J. 2016

$\mathrm{P}-$ value $=0,455>0,05$. $\mathrm{H} 0$ is accepted. It means that there is not significant difference and the pressure of components has no influence on number of repairs.

\section{Testing of glue travel}

There were made two test with 300 pieces. In the first test we used the standard glue travel and in the second test the glue travel was shifted to the edge of the grundpllate.

Results:

First test: 125 cleaned pieces $(83.3 \%)$

Second test: 133 cleaned pieces $(88.6 \%)$

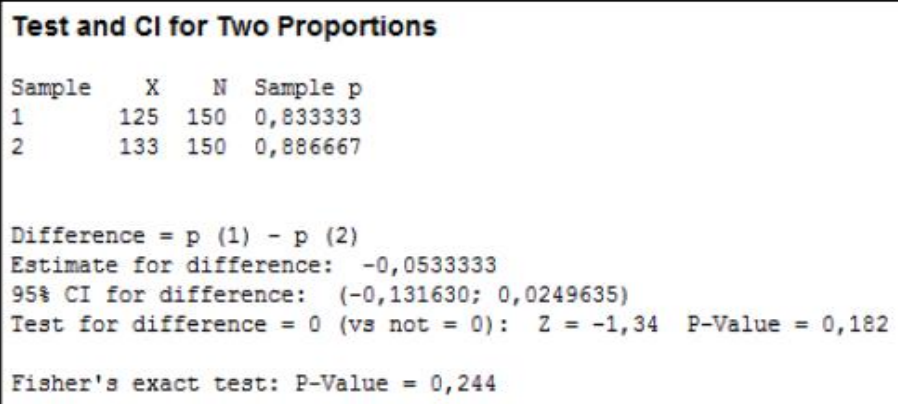

Fig. 9. Testing of glue travel. 
$\mathrm{P}-$ value $=0,182>0,05 . \mathrm{H}_{0}$ is accepted. It means that there is not significant difference and the glue travel has no influence on number of repairs.

\section{Testing the amount of glue}

There were made two test with 300 pieces. In the first test we used the standard amount of glue and in the second test we used the half amount. The amount of glue was reduced from $0.5 \mathrm{~g} / \mathrm{pc}$ to $0.25 \mathrm{~g} / \mathrm{pc}$.

Results:

First test: 125 cleaned pieces $(83.3 \%)$

Second test: 28 cleaned pieces $(18.6 \%)$

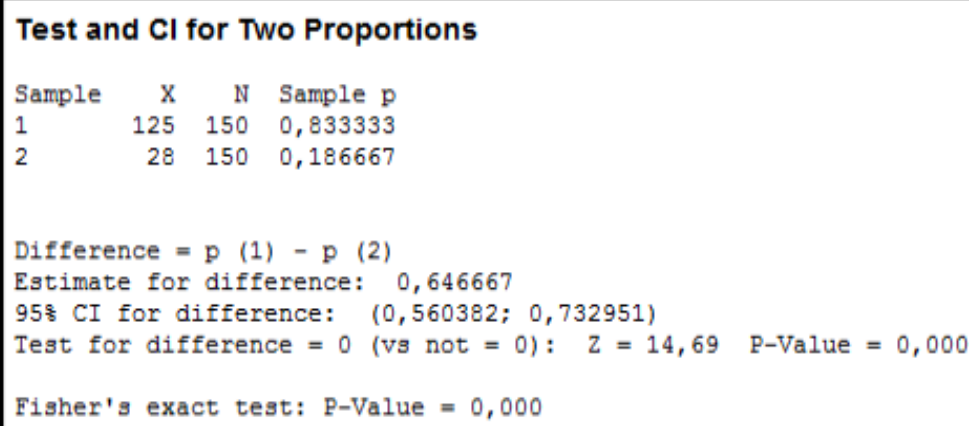

Source: SÝKOROVÁ J. 2016

Fig. 10. Testing the amount of glue.

$\mathrm{P}-$ value $=0,00 . \mathrm{H} 1$ is accepted which means that there is significant difference and the amount of glue has the influence on number of repairs.

\subsection{Improve}

From the analysis in the previous step we have taken a corrective action in the form of an adjustment of glue amount. On IGBT modules family SEMiX3 we began in half of November to apply the glue in half amount according to time Schedule defined in the Define phase.

\subsection{Control}

The proposed corrective actions identified in step Analyze have been implemented into the IGBT modules family SEMiX3 production. We have determined how to collect, record and evaluate the data to see if we've met the goals defined earlier. 
We have also now recorded the data into the correction record form. We have implemented the corrective actions and after that we have followed a three - month period. Our goal was to find out if we were able to reduce the number of repairs on IGBT modules by $50 \%$, as we defined in the first phase Define. New data were compared with the original data before the project started. Results can be seen in Table 8.7.

On the basis of the data we found, that we succeeded in the monitored months after applying the corrective actions to reduce the number of repairs by incredible $92 \%$, which means, that the target was exceeded by $42 \%$.

Table 7. Statistical data in glue applying process in months August, 2015 - February, 2016

\begin{tabular}{|c|c|c|c|c|c|c|}
\hline Month & $\begin{array}{l}\text { No. Of } \\
\text { sticked } \\
\text { pcs }\end{array}$ & $\begin{array}{l}\text { No. Of } \\
\text { cleaned } \\
\text { pcs }\end{array}$ & $\begin{array}{l}\% \text { of } \\
\text { cleaned } \\
\text { pcs }\end{array}$ & $\begin{array}{l}\text { Sigma } \\
\text { level }\end{array}$ & $\begin{array}{l}\% \text { of } \\
\text { cleaned } \\
\text { pcs }\end{array}$ & $\begin{array}{l}\text { Sigma } \\
\text { level }\end{array}$ \\
\hline $\begin{array}{l}\text { August, } \\
2015\end{array}$ & 9500 & 7707 & 81.13 & 1.74 & \multirow{3}{*}{84.10} & \multirow{3}{*}{1.7} \\
\hline $\begin{array}{l}\text { September, } \\
2015\end{array}$ & 16500 & 13792 & 83.59 & 1.79 & & \\
\hline $\begin{array}{l}\text { October, } \\
2015\end{array}$ & 21000 & 18028 & 85.85 & 1.68 & & \\
\hline $\begin{array}{l}\text { December, } \\
2015\end{array}$ & 25200 & 1795 & 7.12 & 3.3 & \multirow{3}{*}{6.65} & \multirow{3}{*}{3.32} \\
\hline $\begin{array}{l}\text { January, } \\
2015\end{array}$ & 33700 & 2217 & 6.58 & 3.35 & & \\
\hline $\begin{array}{l}\text { February, } \\
2015\end{array}$ & 30800 & 1951 & 6.33 & 3.38 & & \\
\hline
\end{tabular}

Source: SÝKOROVÁ J. 2016

\section{Conclusion}

Number of repairs in the module glue applying process represented $84 \%$, which in financial terms means for the enterprise a loss of $€ 7905.4$ in three months. The Six Sigma team managed to reduce the number of repairs of $92 \%$, which was also a considerable financial savings. By 1000 produced pieces, costs linked with corrections for bonding operations decreased from $€ 5011.20$ to $€ 400.70$. The repair of one piece represents the amount of $€ 0.20$.

Saving of costs connected with the half amount of glue in the glue applying process represent for 1000 produced pieces the amount of $€ 108.15$, while the original costs at the beginning were $€ 216.30$. 
This Six Sigma project also brought saving connected with time reducing. If the bonding worker does not need to clean each piece, the is a possibility to increase his capacity to almost to the level of the glue applying device. The machine capacity is $133.20 \mathrm{pcs} /$ hour a the worker's capacity was $82.60 \mathrm{pcs} / \mathrm{hour}$. One piece cleaning takes 12.20 seconds. After corrective actions applying (where the amount of glue was reduced to a half) was the worker's time for cleaning reduced to a 2.80 seconds and his capacity will increase to $109.80 \mathrm{pcs} /$ hour.

\section{Bibliography}

1. AiKens C. H. 2011. Quality inspired management. The key to sustainability. New Jersey: Pearson Education, Inc., publishing as Prentice Hall. ISBN 10: 0-13-119756-8. ISBN 13: 978-0-13-119756-5. p. 623.

2. ANDRÁSSYOVÁ Z. et al. 2011. Assembly process capability of automotive seats. In Acta Technologica Agriculturae, vol. 14, 2011, no. 3, pp. 74-78.

3. Deming W. E. 2000. The New Economics for Industry, Government, Education. Second Edition. Cambridge, Massachusetts: MIT Press, pp. $131-133$.

4. Ferancová M. et al. 2013. Determining the capability of production equipment. In Advanced Materials Research. Vol. 801, special iss., p. 41 - 49. ISSN 1022-6680.

5. HRUBEC J. et al. 2009. Integrovaný manažérsky systém. Nitra: SPU. ISBN 978-80-5520231-0.

6. JanKajovÁ E., KotUs M. 2015. Reliability evaluation in the production process of aluminium castings. In: Production engineering archives. 6, 1 (2015), s. 49--51. ISSN 2353-5156.

7. KOLSAR P.J. 1994. What Deming Told the Japanese in 1950. Quality Management Journal 2, No. 1: 14.

8. KORENKO M. 2012. Manažérstvo kvality procesov. Nitra: SPU. ISBN 978-80-552-0789-6.

9. Korenko M., Prístavka M., DrLičKa R. 2015. Quality management processes. Vyd. Nitra: Slovenská pol’nohospodárska univerzita, 144 p. ISBN 978-80-552-1316-3.

10. Kotus M., Jankajová E., PetríK M. 2015. Quality control of aluminium melt in production process. In: Research in agricultural engineering. 61, special iss., pp. 43-47. ISSN 1212-9151.

11. SÝKOROVÁ J. 2016. Application of Six Sigma method in the process of glue applying IGBT modules family SEMiX3.. (diploma thesis). Trnava, STU. Supervisor: Katarína Lestyánszka Škůrková.

12. IsHIKAWA K. 1982. Guide to Quality Control. Tokyo: Asian Productivity Organization.

13. Mizuno S. 1984. Companywide Total Quality Control. Tokyo: Japanese Union of Scientists and Engineers. 
14. Petrík J., Gengel P. 2009. The capability of green sand mold strength and mold permeability measurement process. Acta Metallurgica Slovaca, Vol. 15, No. 2, s. 86 - 92. ISSN 1335-1532.

15. PEtRíK J. et al. 2014. Applied load and calibration of the hardness tester. In: Manufacturing technology. ISSN 1213-2489. Vol. 14, No. 2, p. 31-32.

16. SÜTŐOVÁ A., GRZINČIČ M. 2013. Creation of Defects Catalogue for Nonconforming Product Identification in the Foundry Organization. In: Quality Innovation Prosperity. Roč. 17, č. 2, s. 52-58. ISSN 1335-1745.

17. https://www.isixsigma.com/tools-templates/sipoc-copis/sipoc-diagram/

18. https://www.isixsigma.com/dictionary/voice-of-the-customer-voc/

19. https://www.qualtrics.com/research-suite/voice-of-customer/

20. http://support.minitab.com/en-us/minitab/17/topic-library/basic-statistics-andgraphs/hypothesis-tests/basics/what-is-a-hypothesis-test/

21. http://stattrek.com/hypothesis-test/hypothesis-testing.asp

22. http://asq.org/learn-about-quality/six-sigma/overview/dmaic.html 